\title{
The Effects of Propulsion System Operation on Military Aircraft Survivability
}

\author{
Aristeidis Antonakis ${ }^{1}$, Theoklis Nikolaidis ${ }^{2}$ and Pericles Pilidis ${ }^{3}$ \\ Propulsion Engineering Centre, Cranfield University, Cranfield, UK, MK43 OAL
}

\begin{abstract}
The recent advances in Infra-Red (IR) weapon technology have dramatically altered the rules of air combat leading to a consistent departure from 'traditional' EnergyManeuverability philosophy in aircraft design, prioritizing stealth and sophisticated armament instead. In this modern aerial warfare environment, it is obvious that new techniques need to be applied to properly assess aircraft survivability and produce successful designs for aircraft propulsion systems. The present study focuses on the development of such a methodology, which contrary to related work in the field includes considerations for both aircraft IR signature and missile/aircraft kinematic performance. An aircraft IR signature model is constructed using a collection of methods for area $\&$ temperature estimation and exhaust plume modelling; the latter is combined with missile-vs-aircraft and aircraft-vsaircraft simulations to quantify aircraft survivability in the form of missile \& aircraft lethal zones. The proposed methodology is applied to a study on propulsion system effects on aircraft survivability, in which a comparison between different engine configurations is performed: In the scenarios examined, IR signature at cruise conditions and maximum-power thrust performance are identified as key parameters for aircraft combat performance.
\end{abstract}

\section{Nomenclature}

(Nomenclature entries should have the units identified)

$$
\begin{aligned}
& A=\text { Area } \\
& A B=\text { Afterburner }
\end{aligned}
$$

\footnotetext{
1 PhD Researcher, Propulsion Engineering Centre, Cranfield University, Cranfield, UK, MK43 0AL, a.antonakis@cranfield.ac.uk

2 Lecturer, Propulsion Engineering Centre, Cranfield University, Cranfield, UK, MK43 0AL, t.nikolaidis@cranfield.ac.uk

3 Professor, Propulsion Engineering Centre, Cranfield University, Cranfield, UK, MK43 0AL, p.pilidis@cranfield.ac.uk
} 


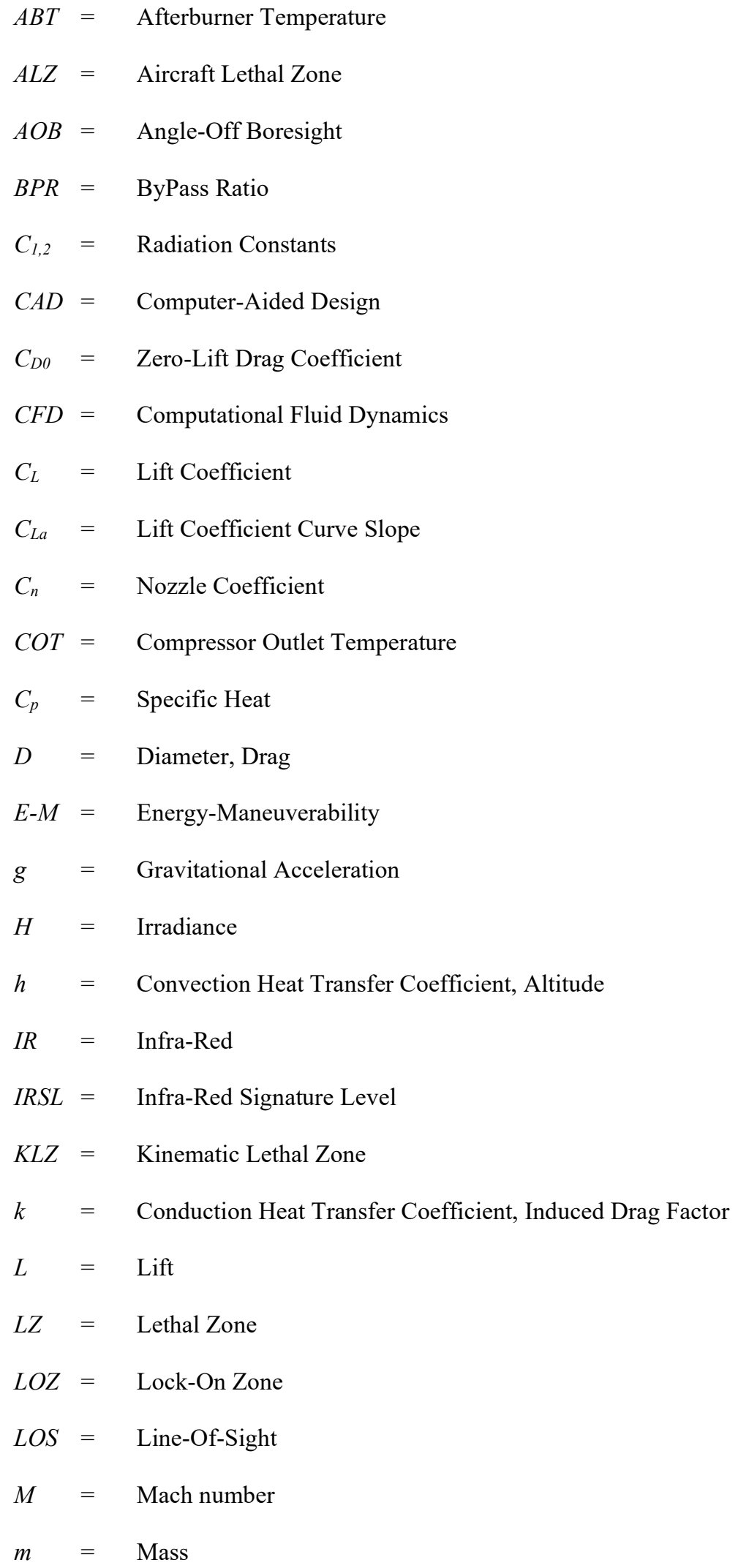




$$
\begin{aligned}
& m_{p} \quad=\quad \text { Propellant Mass } \\
& N=\text { Radiance } \\
& N_{c}=\text { Navigation Constant } \\
& n_{z}=\text { Load factor } \\
& p \quad=\quad \text { Roll Rate } \\
& P R=\text { Pressure Ratio } \\
& \text { PSO = Particle Swarm Optimization } \\
& \dot{Q}=\text { Heat Flux } \\
& R=\text { Distance } \\
& S=\text { Wing Reference Area } \\
& \text { St }=\text { Stanton Number } \\
& T=\text { Temperature, Thrust } \\
& t_{B}=\text { Propellant Burn Time } \\
& T R=\text { Temperature Ratio } \\
& V \quad=\quad \text { Velocity } \\
& V R=\text { Velocity Ratio } \\
& W \quad=\quad \text { Radiant Emittance } \\
& \alpha=\text { Angle of Attack, Acceleration } \\
& \beta=\text { Jet Expansion Angle } \\
& \gamma \quad=\quad \text { Flight Path Angle } \\
& \varepsilon=\text { Emittance } \\
& \eta \quad=\quad \text { Isentropic Efficiency } \\
& \lambda=\text { Wavelength } \\
& \xi=\text { Aileron Deflection } \\
& \rho \quad=\quad \text { Fluid Density } \\
& \sigma=\text { Stephan-Boltzmann Constant } \\
& \tau=\text { Transmittance } \\
& \tau_{\alpha} \quad=\quad \text { Angle of Attack Time Constant }
\end{aligned}
$$




$$
\begin{aligned}
& \varphi \quad=\text { Bank Angle } \\
& \psi \quad=\text { Yaw Angle } \\
& \omega \quad=\quad \text { Angular Velocity }
\end{aligned}
$$

\section{I.Introduction}

$\mathrm{A}^{\text {ccording to Planck's law of radiation, warm bodies emit radiation with spectrum and intensity that depend upon }}$ their surface temperature and material properties. The aerodynamic interference between an aircraft's external surface and the atmosphere, combined with the massive heat output of its propulsion system, generate high-temperature regions over and around the airframe, which act as sources of radiation in the infrared (IR) spectrum. Ever since the early 1950's, dedicated devices, called IR seekers, have been developed to exploit this property for locating and destroying aircraft targets by directing missiles against them. IR seekers allow for passive detection and tracking of aircraft, which, contrary to active detection methods such as radar, gives no warning to the target [1]. The improvements in seeker technology that have been introduced during the last three decades have dramatically altered air-to-air combat rules and tactics: new long-range highly-maneuverable weapons have been introduced increasing engagement distances and putting more emphasis on the capabilities of the onboard sensors than on the maneuverability of the aircraft itself. As a consequence, in this modern aerial warfare environment, careful management of aircraft IR Signature Level (IRSL) has become a necessity in order to improve the survivability and combat effectiveness of military aircraft [2].

Traditionally, Boyd's Energy Maneuverability (E-M) Theory [3] is used to measure aircraft survivability in terms of turn performance and acceleration capability; this approach was effectively applied to the design of well-performing fighters such as the F-16 and the F-15 during the 1960's and 1970's. Following the recent improvements in weapon technology, however, skepticism has been raised about whether Energy-Maneuverability is still suitable for describing combat performance in a modern warfare environment: During the last decades, military aircraft design has demonstrated a consistent departure from this philosophy, prioritizing stealth and sophisticated weaponry instead. This trend has become more obvious than ever after the introduction of the F-35 fighter aircraft, whose design, for the first time, trades maneuverability for radar invisibility and has consequently become the subject of much controversy $[4]$. 
A recent study [5], emphasizes on the gradual departure from traditional 'tail-chasing' fight that has begun after the introduction of effective, long-range, all-aspect IR weapons in the 1980's: Future combat is expected to involve very little or no maneuvering at all and will mostly rely on sensor networks, data fusion and smart, long-range weapons. In this context, it is reasonable to question the relation between aircraft maneuverability and combat effectiveness: if this connection no longer exists, it would be reasonable to dispense with fuel-thirsty power plants and switch to more efficient solutions that will boost mission range and reduce detectability. On the other hand, one must be cautious not to repeat mistakes of the past: back in the 1960's, tacticians anticipated that future combat would solely rely on missiles and take place at supersonic speeds, a change that has yet to occur more than half a century later [6]. However, in any case it is well understood that, with the advent of new weapon technologies, new methods are also required to gain an insight on the requirements of the evolving aerial battlefield. Such predictions will be necessary to ensure the viability of future aircraft and engine projects given the constantly rising investments in both money and time that are required to complete their development [7].

The extensive use of IR weapons against aircraft targets has been the motivation for the development of models to estimate aircraft IR signature such as SPIRITS [8], SIRUS [9] and NATO's NIRATAM [10] codes. Several studies have also been published in the field, attempting to quantify the effect of IR signature on aircraft survivability: Mahulikar et al. [11] proposed a component-based method for IR signature prediction for complete airframes and used it to impose constraints on the aircrafts' flight envelope to avoid exposure to ground-to-air IR threats. Jianwei \& Qiang [12] used a coupling between a CFD solver estimating aircraft skin temperature and a reverse Monte-Carlo model for radiation transfer to produce a detailed representation of the IR Signature Level (IRSL) of a fighter jet and assess the individual contribution of various aircraft components to it. Kim et al. [13] employed a similar approach for IRSL estimation and combined it with a simple missile kinematic model to assess aircraft susceptibility to IR-guided air-toair missiles. Apart from high-fidelity solutions, simplified representations of aircraft IRSL are of some practical value and have also been used in several studies related to aircraft survivability: The work of Rao and Mahulikar [14], expanded in [15] [16], is based upon an isotropic aircraft IR radiation model, which, similarly to reference [13], is combined with a simple missile model to estimate missile lethal range as a function of aircraft and missile flight parameters. In the same context, Andersson [17] studies the effect of skin emissivity on the effectiveness of attack aircraft against IR-guided SAM sites by means of a very simplified representation of aircraft geometry. 
Predicting aircraft IRSL is only part of the process for assessing aircraft survivability against IR threats as it only considers the ability of the weapons' sensors to lock-on to the target and track its movement; in practice, to destroy a manoeuvring target, the weapons must also have the kinematic ability to reach at a sufficient distance close to it so that the detonation of the warhead becomes effective. In addition to this, in an air-to-air combat scenario, the attacker needs to have sufficient manoeuvrability to place himself in a position that his weapons have a high probability of hitting the target [18] [19]. As a result, a complete simulation of such a scenario is a highly complicated task and a lot of research has been conducted on the development of tools to be used for the evaluation of suitable aerial tactics: this is signified by a plethora of proposed methodologies that attempt to provide solutions to aircraft-vs-aircraft and aircraft-vs-missile combat manoeuvring problems. Generally, these are classified into those which formulate an optimization problem and use a suitable solver to solve it [20] [21] [22] [23] [24] [25] and rule-based methods [26] [27] [28] [29], the former emphasizing on the optimality of the generated solutions and the latter targeting towards reduced computational complexity and real-time applications.

Quite surprisingly, none of the studies published in the open literature combine all the tools stated above (IR signature models, aircraft-vs-missile and aircraft-vs-aircraft simulations) to produce exact estimates of aircraft survivability against IR threats. Therefore, this work formulates a complete methodology for assessing aircraft survivability including considerations about both aircraft IR signature and missile/aircraft dynamics and uses it for conducting aircraft-engine integration studies. The proposed method does consider survivability against radar-guided weapons, which, however, may be studied in a completely similar fashion by replacing the aircraft IR signature model with an equivalent one for Radar Cross Section (RCS) prediction.

The structure of this article is as follows: Section II describes the methods followed for the construction of aircraft IR and aircraft/missile kinematic models, along with details on case setup for the simulations conducted. Section III presents an example application of the proposed methodology, in the context of which a comparison between two different aircraft/engine configurations is used to provide insights on the interconnection between propulsion system performance and aircraft survivability. Finally, conclusions from the numerical experiments are summarized in Section IV, followed by suggestions for further research in Section V.

\section{II.Methodology}

\section{A. Aircraft IR signature model}




\section{Model Structure}

According to Planck's law of radiation, a body's radiant emittance W is given by the formula:

$$
W(\lambda)=\frac{\varepsilon(\lambda) C_{1}}{\lambda^{5}\left(\exp \left(\frac{C_{2}}{\lambda T}\right)-1\right)}
$$

where $C_{1}, C_{2}$ are the first and second radiation constants, $\varepsilon$ is the body's emittance, $\mathrm{T}$ is the body temperature and $\lambda$ is the radiation's wavelength. The body's radiance $\mathrm{N}$ in the band $\left(\lambda_{1}, \lambda_{2}\right)$ is then given by:

$$
N=\frac{1}{\pi} \int_{\lambda_{1}}^{\lambda_{2}} W(\lambda) d \lambda
$$

The irradiance $\mathrm{H}$ at some arbitrary point $x_{0}$ located at distance $\mathrm{R}$ from the body equals:

$$
H=\frac{A \tau}{\pi R^{2}} N
$$

where $\mathrm{A}$ is the body's projected area when viewed from $x_{0}$ and $\tau$ accounts for atmospheric transmittance, which is the ratio of the radiation flux at distance $\mathrm{R}$ to the radiation flux at the source. The value of transmittance $\tau$ is a function of the atmospheric composition along the path between the source and the observation point, and accounts for the strong influence of the atmosphere on the transmission of IR signals. Although hereby, for the sake of simplicity, $\tau$ is presented as a scalar value, in fact, this is also a function of the radiation's wavelength: Particularly for IR, only radiation corresponding to special bands, called 'atmospheric windows' can effectively pass through the atmosphere: these bands are exploited by IR sensors for target identification \& tracking [1] [2].

A source of IR radiation may be distinguished from its background by means of the difference in irradiance it generates with respect to radiation originating from the background. This property is called contrast irradiance $\mathrm{H}_{\mathrm{c}}$ and is defined as follows:

$$
H_{c}=H-H_{b g d}
$$

where $\mathrm{H}_{\mathrm{bgd}}$ is the background irradiance. 
An IR detector is able to locate a radiator if the contrast irradiance at the sensor is larger than a threshold that depends on its sensitivity, expressed by its Noise Equivalent Irradiance (NEI) characteristic. Assuming that the emitted radiation consists of wavelengths that lie within the sensor's wavelength band, detection is possible if:

$$
H_{c}>N E I \xi_{\min }
$$

where $\xi_{\min }$ is a number greater than unity. The maximum lock-on range $\left(\mathrm{R}_{\mathrm{LO}}\right)$ may be calculated by combining Eqs (4) and (5):

$$
R_{L O}=\sqrt{\left(N-N_{b g d}\right) \tau \frac{A}{N E I \xi_{\text {min }}}}
$$

Generalizing, for a radiator consisting of a surface with arbitrary shape and temperature distribution:

$$
R_{L O}=\sqrt{\frac{\tau}{N E I \xi_{\min }} \iint_{S}\left(N-N_{b g d}\right)(\bar{x} \cdot \bar{n}) d S}
$$

$\bar{x}$ and $\bar{n}$ represent the Line-Of-Sight (LOS) and surface normal vectors respectively. Eq (7) needs to be solved iteratively, since the atmospheric transmittance $\tau$ is itself a function of the distance $\mathrm{R}_{\mathrm{LO}}$. The same equation defines the requirements for an IR signature model of a generic radiation source: the latter needs to provide estimates for the following quantities:

1. Surface temperature distribution

2. Material emittance properties

3. Projected areas for different fields of view

4. Background radiance

5. Atmospheric transmittance

6. Sensor performance

Adapting the above to an aircraft application leads to the model structure of Figure 1. An aero-propulsive model is used to calculate the engine's operating point and the respective thermodynamic properties of the exhaust gases for the specified flight conditions and aircraft configuration. These are fed as inputs to aircraft and plume thermal models, which estimate spatial temperature distributions for these components. Using Eqs. (1)-(4) in conjunction with an 
atmospheric model which outputs background radiance (for this study, this was based on the LOWTRAN code, assuming sky background and a mid-latitude summer atmospheric model) and atmospheric transmittance along the specified path, contrast irradiance at the sensor is estimated. Finally, Eq. (7) is solved iteratively to obtain the aircraft's lock-on range for a given sensor. Paragraphs II.A.2-4 present a description of the modelling approach used for establishing the radiation models for the aircraft surface components and the engine exhaust plume.

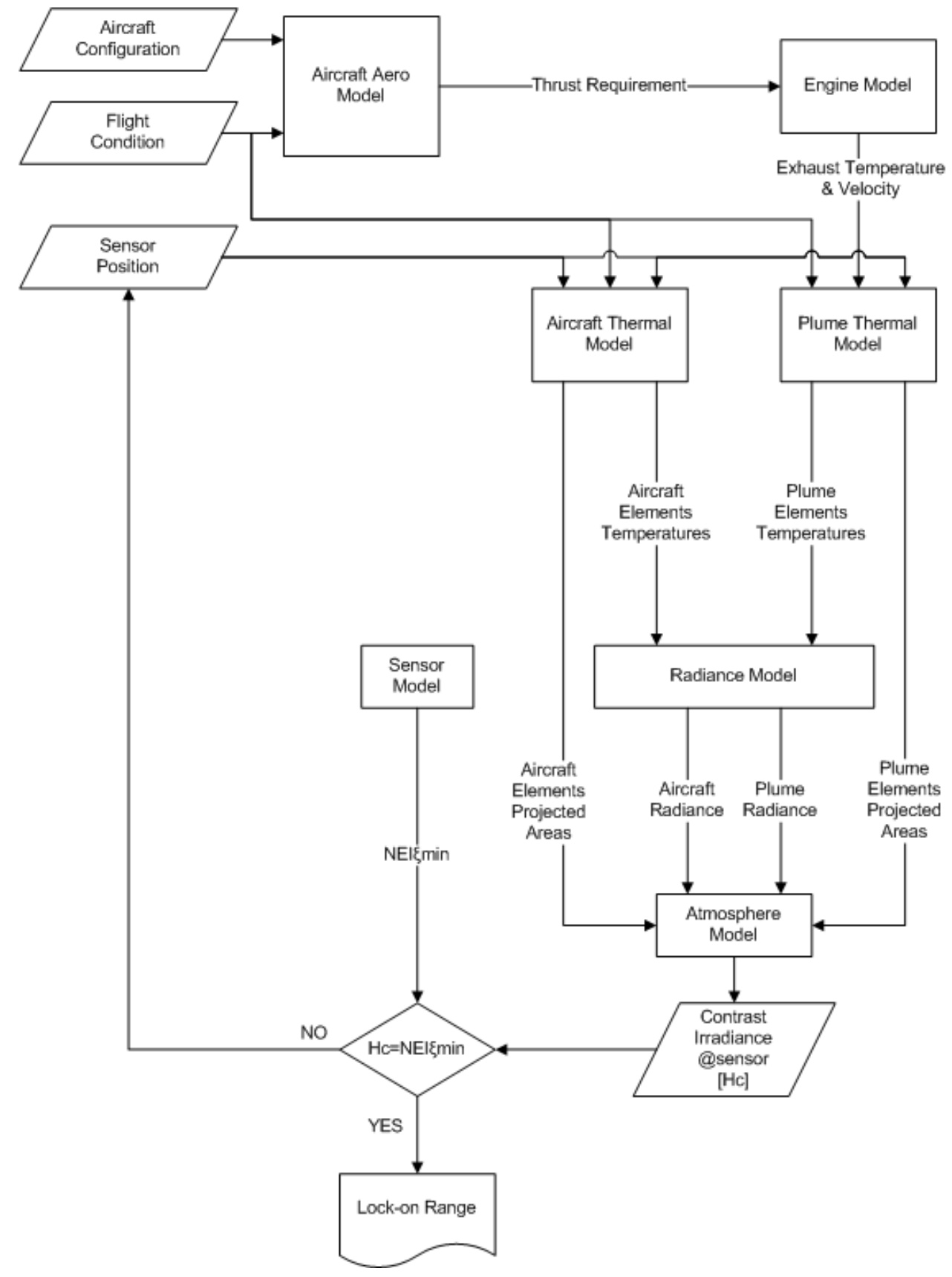

Figure 1: Flowchart of the procedure for estimating aircraft lock-on range 


\section{Skin Temperature Estimation}

Estimating surface temperature distribution for an aircraft in flight requires solving heat-balance equations for the entire airframe which is a complicated task because of the complex flowfield around the aircraft, particularly at transonic and supersonic flight speeds. Researchers have frequently resorted to CFD [12] [13] [30] [31] to generate solutions for the aircraft heat balance problem, however, as a result of the computational intensity of the calculations involved, the data presented correspond to a limited number of operating conditions and/or do not cover the entire airframe.

With the intention to establish an aircraft IR model that will generate correct-trend-and-magnitude predictions for the entire flight envelope with minimum computational requirements, in this article, a semi-empirical formulation for temperature estimation was selected. Under this scope, the formula proposed in references [2] [17] [32] was used for aircraft skin temperature estimation as per following:

$$
T=T_{\infty}\left(1+0.164 M^{2}\right)
$$

which is essentially a fraction of the flow total temperature at the specified flight condition $\left(T_{\infty}\right.$ accounts for ambient temperature and $M$ for Mach number). This value, however, can only be considered representative of airframe areas not affected by the heat generated by the propulsion system. The latter is known to generate hot regions around the rear fuselage and, in particular, the exhaust tailpipe [1]. An alternative formulation was thus required for these regions, taking into account the power plant's heat output.

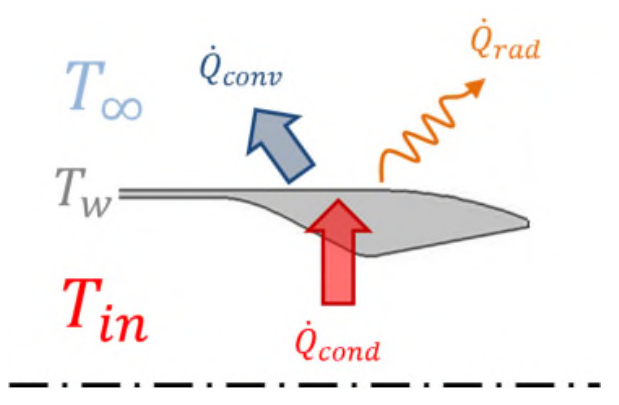

Figure 2: Heat Flow on the exhaust pipe

The heat balance equation for the rear fuselage section of Figure 2 can be written as: 


$$
\dot{Q}_{\text {cond }}=\dot{Q}_{c o n v}+\dot{Q}_{r a d}
$$

where $\dot{Q}_{\text {cond }}$ is the heat flux per unit area transmitted by conduction through the tailpipe's casing, $\dot{Q}_{\text {conv }}$ is the convection heat flux between the tailpipe wall and the airstream and $\dot{Q}_{r a d}$ is the radiation flux. Eq. (9) can be expressed in a more analytical form as:

$$
k\left(T_{i n}-T_{w}\right)=h\left(T_{w}-T_{\infty}\right)+\varepsilon \sigma\left(T_{w}^{4}-T_{\infty}^{4}\right)
$$

where $k, h$ are the conduction and convection heat transfer coefficients respectively, $\sigma$ is the Stephan-Boltzmann constant and $T_{w}$ is the wall temperature. The conduction heat transfer coefficient is a property of the material of the tailpipe's casing and was estimated at $k=10 \mathrm{~W} / \mathrm{m}^{2} \mathrm{~K}$ using data for wall temperature distribution and heat flux found in references [30] [31]. The convection heat transfer coefficient $h$ is a function of the flow properties over the tailpipe's external surface and was estimated using the procedure of ESDU item no 69011 [33] as a function of flight conditions. The method is based on the flow Stanton number $(\mathrm{St})$ :

$$
S t=\frac{h}{\rho V C_{p}}
$$

where $\rho$ is the fluid's density, $C_{p}$ is the fluid's specific heat and V the flow velocity. Stanton number is a function of the wall temperature, therefore, an iterative procedure was set up to solve of Eq. (10) and obtain the temperature of the external tailpipe wall $\mathrm{T}_{\mathrm{w}}$ for each operating condition.A much simpler approach was used to estimate the bulk metal temperature of the Low-Pressure Turbine disk which is the main radiating component in the rear side of the aircraft [1]: This was set equal to the turbine exit gas temperature, limited to a maximum of $1,200 \mathrm{~K}$ which is representative of the disk material's maximum operating temperature.

The constructed heat-balance model was verified against the data from references [30] [31]. With results being considered satisfactory for the scopes of the intended initial performance study, further validation using CFD, together with the introduction of higher-fidelity models for airframe radiation expanded to take into account the surface temperature reduction that can result from the application of thermal insulation or cooling where left for future work on the project. 


\section{Plume Model}

Apart from the airframe itself, studies on the IR signature of air vehicles [34] have shown that a major contributor to a military aircraft's IR footprint is the exhaust plume formed by the exhaust gases exiting the engine's nozzle. The shape of the exhaust plume and the temperature distribution within it is a function of the internal (engine) and external (atmosphere) flow conditions in the region surrounding the exhaust nozzle. As for the case of aircraft skin temperature estimation, reasonably accurate solutions may be generated by means of CFD, however, the computational cost of this approach makes it, by today's standards, unsuitable for large-scale parametric performance studies. Alternative approaches that are commonly used include empirical methods and the method of characteristics [35].

In the context of the present study the authors resorted to a computationally inexpensive, lower-fidelity method, to allow for its implementation to air combat scenario simulations without this resulting to unacceptable simulation time. The methodology employed combines an empirical velocity distribution from reference [36] with turbulent jet theory [37] and engine operation data from an aircraft manual [38]. This may be summarized as follows: Reference [36] suggests that the non-dimensional velocity ratio (VR) along the plume centerline can be expressed as a function of the corrected distance $x^{*}$ from the nozzle exit plane:

$$
\begin{gathered}
V R=\frac{V-V_{\infty}}{V_{j}-V_{\infty}}=f\left(x^{*}\right) \\
x^{*}=\left[x\left(C_{n} D_{e} \sqrt{1+M_{j}}\right)^{-1}\right]^{b}, b=1+\frac{1}{3}\left[\left(\frac{V_{j}}{V_{0}}\right)^{2}-1\right]^{-1}
\end{gathered}
$$

Where $D_{e}$ accounts for the nozzle diameter whereas $C_{n}$ is a non-dimensional coefficient whose value depends on the nozzle configuration. The use of VR to describe the exhaust flowfield is advantageous in that it can be applied to various combinations of flight velocity $V_{\infty}$, exhaust velocity $V_{j}$ and Mach number $M_{j}$ at the nozzle. Using Eq. (11) as a baseline, a function describing the variation of jet velocity along the plume centerline was constructed by curvefitting on exhaust flowfields sourced from reference [38]. The latter correspond to the rather old J79 turbojet engine but are representative of a generic fully-mixed circular exhaust jet which remains a common configuration among modern military turbofan engines which will be the subject of this study. Following that, axisymmetric shape functions were used to form three-dimensional velocity contours based on the estimated velocities on the jet centerline, as per 
Figure 3. The assumption of an axisymmetric flowfield restricts the model's application to circular exhaust nozzles; an expansion of the method to take into account non-circular nozzle configurations (shown to enhance mixing and reduce aircraft IR signature [39]) was considered as part of future work on the project. To account for the effects of forward velocity on the shape of the exhaust jet, as suggested by the theory of turbulent jets [37], the jet expansion angle $\beta$ was modified according to the formula:

$$
\beta=\beta_{\left[V_{\infty}=0\right]} \frac{V_{j}-V_{\infty}}{V_{j}+V_{\infty}}
$$

The transformation described in Eq. 12 introduces a 'compression' to the original plume shape with increasing freestream flow velocity (Figure 3). Abramovich [37] also suggests that local values of VR are interconnected to the respective values of the non-dimensional temperature ratio (TR).

$$
T R=\frac{T-T_{\infty}}{T_{j}-T_{\infty}}
$$

Therefore, having established the velocity distribution within the plume, an equivalent temperature distribution was constructed in a similar manner, by curve-fitting velocity and temperature data from the same reference [38].

For validation purposes, the predictions generated by the proposed plume model were compared against CFD solutions for fully expanded (Figure 4) and under-expanded nozzle exit conditions [40] (Figure 5). In the fully expanded case, jet exhaust velocity was $550 \mathrm{~m} / \mathrm{s}$, exhaust temperature was $750 \mathrm{~K}$, ambient temperature $288 \mathrm{~K}$ and flight Mach number 0.9. The respective flow conditions for the under expanded nozzle case were jet exhaust velocity $605 \mathrm{~m} / \mathrm{s}$, exhaust temperature $645 \mathrm{~K}$, ambient temperature $212 \mathrm{~K}$ and flight Mach number 0.6 .

Based on the results obtained, the predicted temperature variation along the plume centerline was found to closely match CFD results for the fully-expanded flowfield, resulting in good accuracy in the corresponding plume temperature-area distribution for the same test case (Figure 4). As expected, the model was unable to capture the temperature oscillations present in the under-expanded nozzle solution (Figure 5). These are a result of complex interactions between shock waves and expansion fans occurring within the exhaust jet's inviscid core [41] the effects of which cannot be modelled by the simplified plume representation that was selected. Despite this, temperature predictions were found to be adequately close to the actual results, showcasing a similar reduction trend to the CFD solution results with increasing distance from the nozzle exit. The validity of the assumption for angle $\beta$ was assessed 
by comparing the CFD plume boundary with the corresponding boundary generated by the model: good match between the two results was observed, only limited by the proposed model's inability to capture the initial plume deflection due to the expansion taking place at the nozzle exit. Subject to the above limitations, the proposed method's performance was deemed sufficient for the intended preliminary-level performance studies.
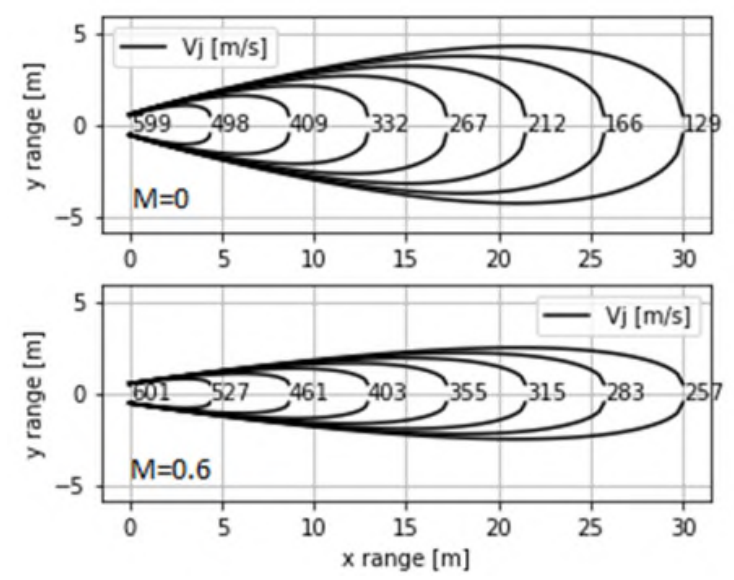

Figure 3: Comparison between plume shapes for zero freestream velocity [top] and freestream Mach $=0.6$ [bottom].

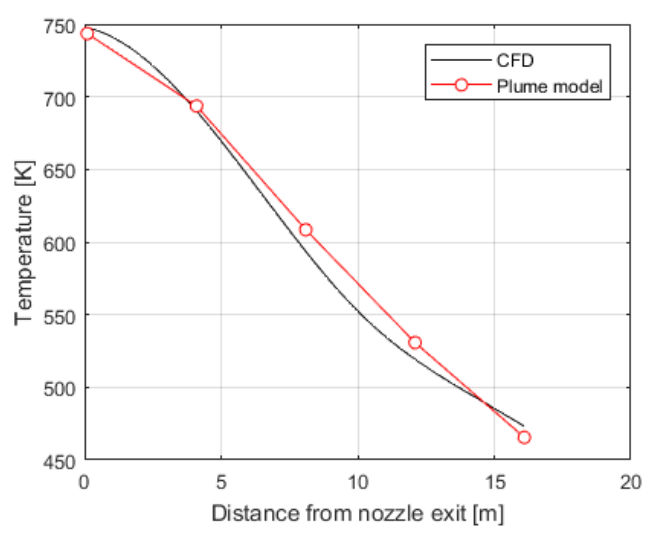

(a)

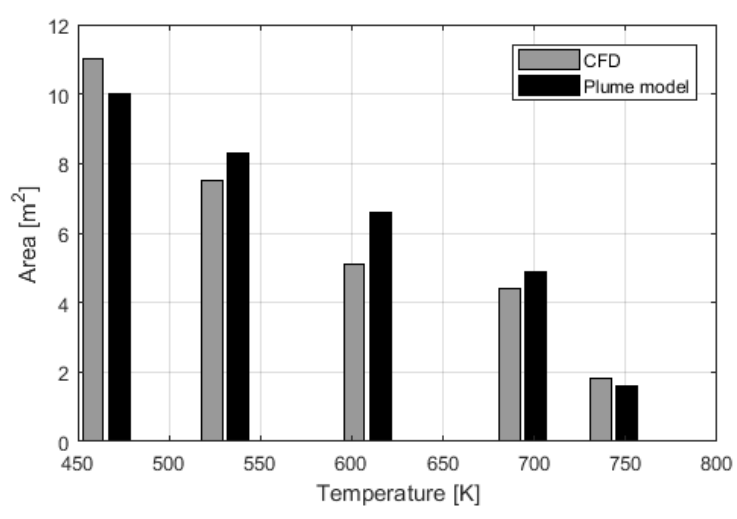

(b)

Figure 4: Plume model predictions vs CFD data for a fully expanded nozzle case: (a) Jet temperature along centerline vs distance (b) Temperature vs element area. 


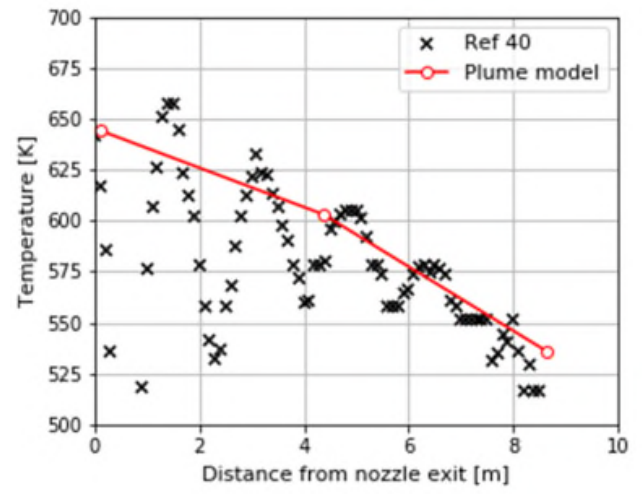

(a)

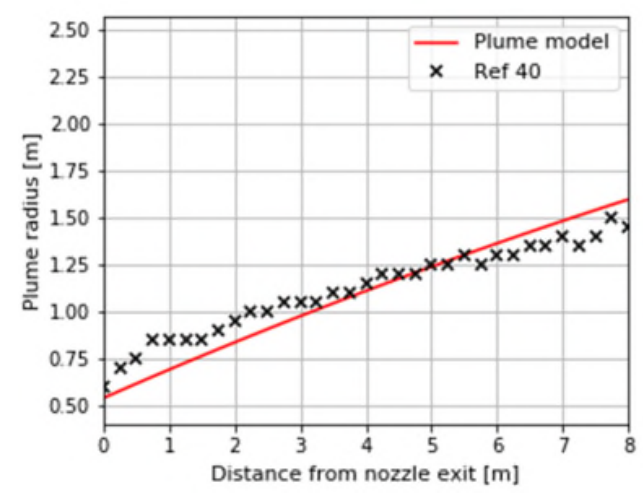

(b)

Figure 5: Plume model predictions vs CFD data for an under-expanded nozzle case from reference [40]: (a) Jet temperature along centerline vs distance (b) Plume width vs distance.

\section{Estimation of component projected areas}

According to Eq. (4), the total irradiance generated at the sensor is proportional to the projected area of each radiating component. Therefore, aside temperature estimates, component area estimates should also be as realistic as possible in order to obtain physically correct results in terms of the distribution of IR radiation levels around the aircraft. Whereas aircraft and plume geometries can be reduced to very simple shapes (for example, reference [17] uses a 'shoebox' aircraft model and reference [42] models the exhaust plume as two concentric cylinders) while retaining some accuracy on the projected area estimates from different fields of view, such an approach fails to capture the exact effects of overlaps between them which are fundamental for aircraft IR: when viewed from the front, it is known that the aircraft body hides most of the engine's exhaust plume from an IR sensor, however, depending on the engine operating condition, some high-temperature regions may still be visible to the sensor and affect the detection range. The same also applies to aircraft side views in which the visibility of high-temperature components is subject to particular features of the aircraft geometry such as the wing span and the location of the empennage with respect to the engine tailpipe.

Based on the above, it was decided to develop a realistic aircraft representation using an open-source CAD design of a generic airframe and exploit it to obtain accurate aircraft area estimates. In this context, a surface grid was generated and used in conjunction with the plume model of the previous paragraph to calculate projected areas for the airframe components and the exhaust plume. The general layout of the airframe grid is shown in Figure 6. 


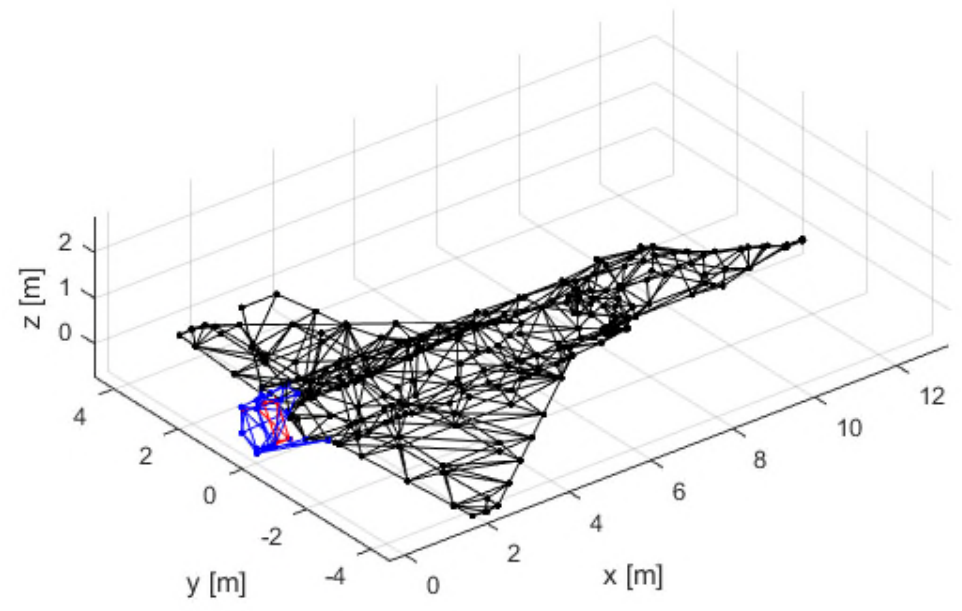

Figure 6: Aircraft surface grid used for calculating projected areas for IRSL estimation. The blue, red and black-colored regions correspond to the tailpipe, turbine face and skin respectively.

To reduce the computational intensity of future IR signature calculations, the spatial domain around the aircraft was parametrized using spherical coordinates and multiple runs were conducted to calculate and store the projected area values. This did not apply to plume projected areas, which need to be re-calculated in every case because plume geometry is a function of the flight conditions and engine setting and, therefore, results were harder to generalize. Figure 7 presents an example calculation of the distribution of IR emissions for an aircraft at cruise.

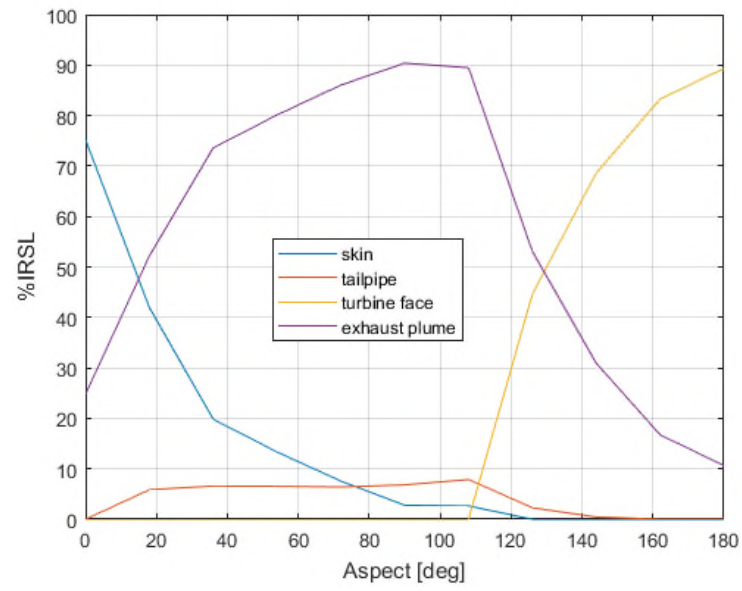

Figure 7: IRSL vs aspect angle for various aircraft components for an aircraft cruising at Mach 0.6 and Altitude $5000 \mathrm{~m}$. 


\section{B. Kinematic Modelling}

\section{Aircraft Dynamic Model}

An 8-state aircraft model was employed to construct a representation of aircraft kinematics, assuming a no-sideslip condition. The model's equations are as follows:

$$
\begin{gathered}
\dot{V}=\frac{T \cos a \dot{-} D}{m}-g \sin \gamma \\
\dot{\gamma}=\frac{(L+T \sin a) \cos \varphi}{m V}-\frac{g \cos \gamma}{V} \\
\dot{\psi}=\frac{(L+T \sin a) \sin \varphi}{m V \cos \gamma} \\
\dot{j}=c_{1} p+c_{2} \xi \\
\dot{\varphi}=1 / 2 \rho V^{2} S\left(C_{D_{0}}+k C_{L}^{2}\right) \\
\dot{\varphi}=1 / 2 \rho V^{2} S C_{L_{a}} a \\
\dot{y}=V \cos \gamma \sin \psi \\
\dot{\alpha}=\frac{a_{c}-a}{\tau_{\alpha}} \\
\end{gathered}
$$


Angle-of-attack $(a)$, Lift $(L)$ and roll rate $(\dot{\varphi})$ being subject to the following constraints:

$$
\begin{gathered}
|a| \leq a_{\max } \\
|L|=\min \left\{1 / 2 \rho V^{2} S C_{L_{a}}|a|, n_{z_{\max }} g\right\} \\
|p| \leq p_{\max }(a) \\
|\xi| \leq \xi_{\max }
\end{gathered}
$$

Eqs. (25)-(28) represent the aircraft's maximum angle of attack capability, structural strength, roll rate limit and maximum aileron deflection respectively. Table 1 contains the parameter values used to create a model of a generic single-engine fighter aircraft.

Table 1: Aircraft Parameters

\begin{aligned} \hline Parameter & Value \\ \hline$m & =8500 \mathrm{~kg} \\ S & =25 \mathrm{~m}^{2} \\ C_{L_{a}} & =0.07 / \mathrm{deg} \\ C d_{0} & =0.015($ subsonic $) \\ k & =0.045($ supersonic $) \\ a_{\max } & =15 \mathrm{deg} \\ \tau_{\alpha} & =0.1 \mathrm{~s} \\ P_{\max } & =270 \mathrm{deg} / \mathrm{s}($ zero - lift $) \\ \xi_{\max } & =20 \mathrm{deg} \\ c_{1} & =-2.5 / \mathrm{s} \\ c_{2} & =0.76 \mathrm{rad} / \mathrm{deg} \mathrm{s}^{2} \\ k_{p} & =20 \\ k_{d} & =4\end{aligned}$

An interface with Turbomatch [43], a Gas Turbine performance simulation tool developed by the Propulsion Engineering Centre at Cranfield University, was used to construct the engine models which were employed to generate thrust maps for the aircraft simulation (term $\mathrm{T}$ in Equations 13-15), as a function of the engine power setting and flight condition. Turbomatch comprises several pre-programmed modules, which correspond to thermodynamic models of components and are called up to evaluate the engine output, i.e. thrust or power, specific fuel consumption, etc. Its 
modularity, which is supported by the implementation of generic component maps, enables the detailed design of any gas turbine configuration.

6. Missile dynamic model

The missile was modelled as a point-mass, as per Eqs. (29)-(36).

$$
\begin{gathered}
\dot{V}_{m}=\frac{T_{m}-\dot{D_{m}}}{m_{m}}-g \sin \gamma_{m} \\
\dot{a_{p}}=\frac{a_{p_{c}}-a_{p}}{\tau_{\alpha_{m}}} \\
\dot{a}_{y}=\frac{a_{y_{c}}-a_{y}}{\tau_{\alpha_{m}}} \\
\dot{\gamma}_{m}=\frac{a_{p}-g \cos \gamma_{m}}{V_{m}} \\
\dot{\psi}_{m}=\frac{a_{p}}{V_{m} \cos \gamma_{m}} \\
\dot{x}_{m}=V_{m} \cos \gamma_{m} \cos \psi_{m} \\
\dot{y}_{m}=V_{m} \cos \gamma_{m} \sin \psi_{m} \\
\dot{h}_{m} \sin \gamma_{m}
\end{gathered}
$$

The model's parametrization is shown in Table 2: the data, sourced from reference [28], correspond to a generic short-range IR-guided missile. Missile thrust $\left(T_{m}\right)$ was assumed to be constant for all flight conditions that were evaluated. Equations (25)-(26) also apply to the missile case. 
Table 2: Missile model parameters

\begin{aligned} & \hline Parameter Value \\ & \hline$m_{m}=90 \mathrm{~kg} \\ & S_{m}=0.03 \mathrm{~m}^{2} \\ & C_{L_{a_{m}}}=0.61 /$ deg \\ &$C d_{0_{m}}=0.75($ subsonic $) \\ & k_{m}=0.1($ supersonic $) \\ & a_{\text {max }_{m}}=30 \mathrm{deg} \\ & \tau_{\alpha_{m}}=0.2 \mathrm{~s} \\ & T_{m}=15,000 \mathrm{~N} \\ & t_{B}=5 \mathrm{~s} \\ & m_{p}=20 \mathrm{~kg} \\ & n_{z_{\max m}}=30 \\ &$\hline \hline\end{aligned}

\section{Engagement Scenarios}

In the context of the present study, two separate simulation scenarios were examined, considering missile-vsaircraft and aircraft-vs-aircraft scenarios. Details on the setup of each scenario are given in Paragraphs II.C.7-8.

\section{Missile-vs-Aircraft scenario}

A missile-vs-aircraft simulation was used to study the effect of missile and aircraft dynamics on the missile lethal envelope expressed by constructing target-centered Kinematic Lethal Zones (KLZ), as per Figure 8. In each simulation scenario, the missile was initialized at a distance $\mathrm{R}$ from the aircraft, at the same altitude and airspeed with its nose pointed to the target or offset by some arbitrary angle (Angle Off-Boresight - AOB) and guided to the target using proportional navigation. The target used the anti-proportional navigation scheme of reference [28] to evade capture. The latter is summarized as follows:

The normal acceleration command generated by pure proportional navigation guidance is given by the formula:

$$
\begin{gathered}
a_{y_{c}}=N_{c} \omega_{y} V_{c} \\
a_{p_{c}}=N_{c} \omega_{p} V_{c}+g \cos \gamma
\end{gathered}
$$


where $N_{c}$ is the navigation constant, $V_{c}$ is the closure velocity and $\omega_{p}, \omega_{y}$ correspond to the pitch and yaw components of the Line-Of-Sight (LOS) rate vector. Imado [28] established a guidance law for missile evasion by reversing the sign of the $\omega$ components and rotating by an arbitrary angle $\eta$. The resulting guidance formula then becomes:

$$
\begin{gathered}
a_{y_{c}}^{\prime}=-a_{p_{c}} \sin \eta+\alpha_{y_{c}} \cos \eta \\
a_{p_{c}}^{\prime}=a_{p_{c}} \cos \eta+\alpha_{y_{c}} \sin \eta
\end{gathered}
$$

By varying angle $\eta$, Imado was able to demonstrate various established, 'textbook' aircraft evasive manoeuvers while conducting large-scale simulations in the parameter space. In the present study, an optimization solver was used instead of a brute-force search to find optimal values for the navigation constant $N_{c}$ and angle $\eta$ that maximize timeto-intercept $t_{i}$. The latter equals the time required for the missile to approach the target at a distance $R$ equal to the warhead's lethal radius $R_{w}$.
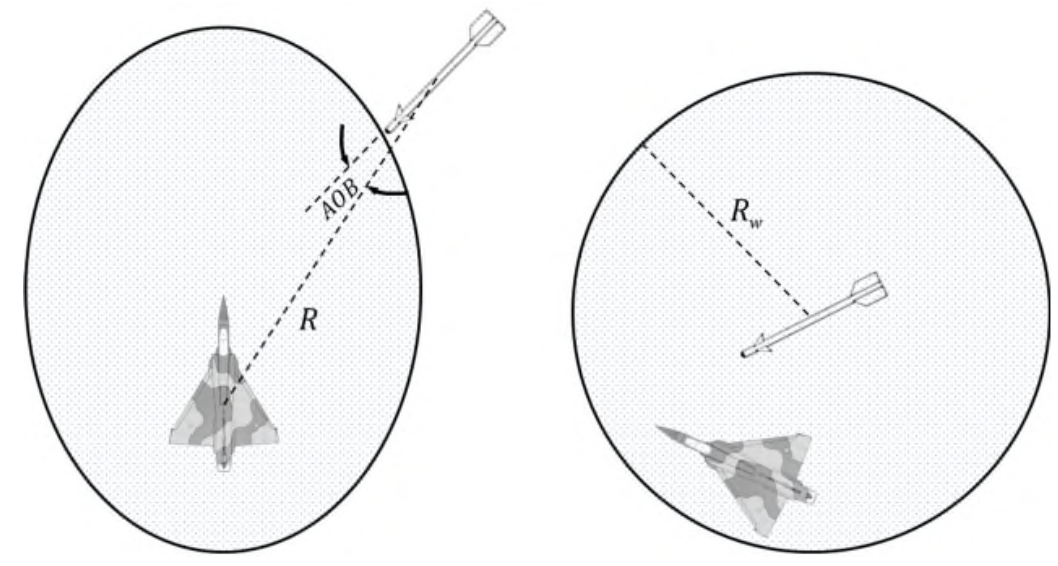

Figure 8: Simulation initialization [left] and intercept condition [right]. The shaded ellipse on the left corresponds to the missile's target-centered kinematic launch success zone.

Given the above description, the respective optimization problem can be formally expressed as:

$$
\max \left\{t_{i}: R\left(t_{i}\right)=R_{w}\right\}
$$


To ensure the global optimality of the generated solutions, given the small dimensionality and unknown structure of the problem, instead of a gradient-based optimization method, Particle Swarm Optimization (PSO) [44] was selected as the optimization solver; population size was set to five particles, leading to converged solutions after 10 generations on average (Figure 9). The result of a typical missile-vs-aircraft scenario is shown in Figure 10.

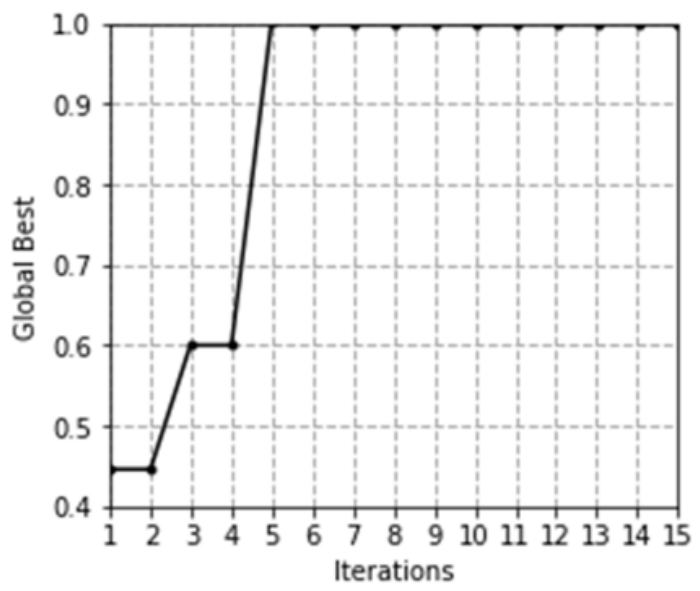

Figure 9: Convergence of the PSO optimization scheme for $N_{c}$ and $\eta$.

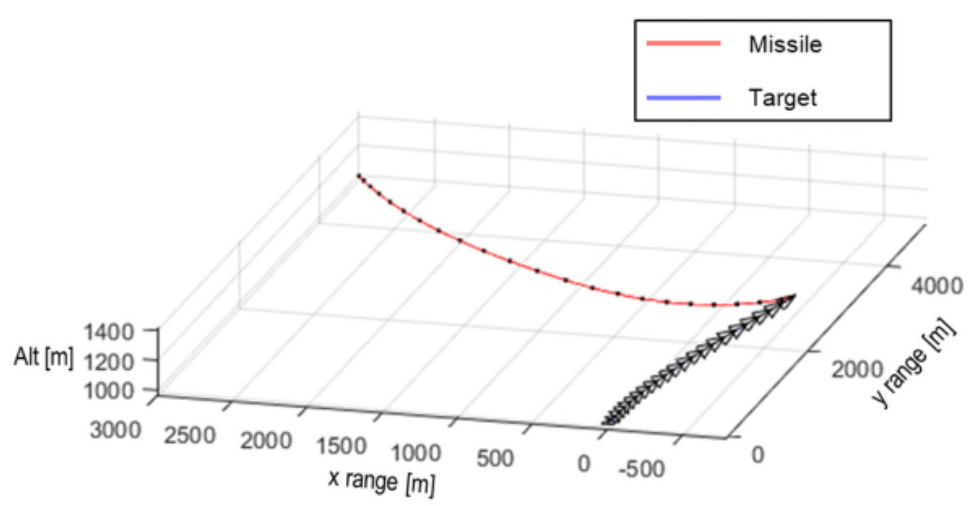

Figure 10: Schematic representation of a typical missile-vs-aircraft simulation scenario; the missile [red] intercepts the aircraft [blue] which attempts an 'away'-type maneuver

\section{Aircraft-vs-Aircraft Scenario}

The case setup for the aircraft-vs-aircraft scenario was identical to that of the missile-vs-aircraft case with two exceptions:

- The attacking aircraft's guidance was switched to a pure pursuit scheme. 
- The termination criterion was not based on the Euclidean distance between the attacker and the evader; instead, the results of multiple runs of the missile-vs-aircraft scenario where used to construct generalized weapon Lethal Zones (LZ), as functions of range, aspect angle and angle-off tail. A "kill" was counted in cases when the evading aircraft remained within the attacker's weapon envelope for time greater than one second (Figure 11).

- Maximum simulation time was set to $40 \mathrm{sec}$ assuming that, given that both aircraft must use the maximum power throttle setting to maximize their maneuverability, the latter constitutes a limit above which the required fuel consumption would typically deter the attacker from performing an attack to the target.
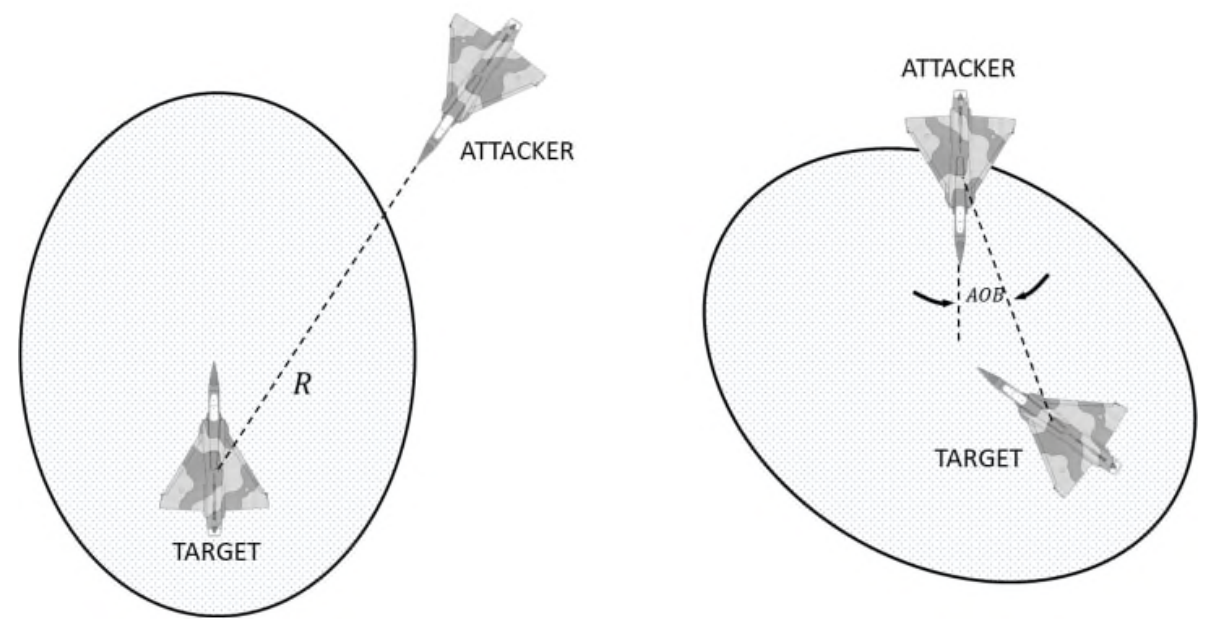

Figure 11: Simulation initialization [left] and intercept condition [right]. The shaded ellipses represent the missile's target-centered envelope. 


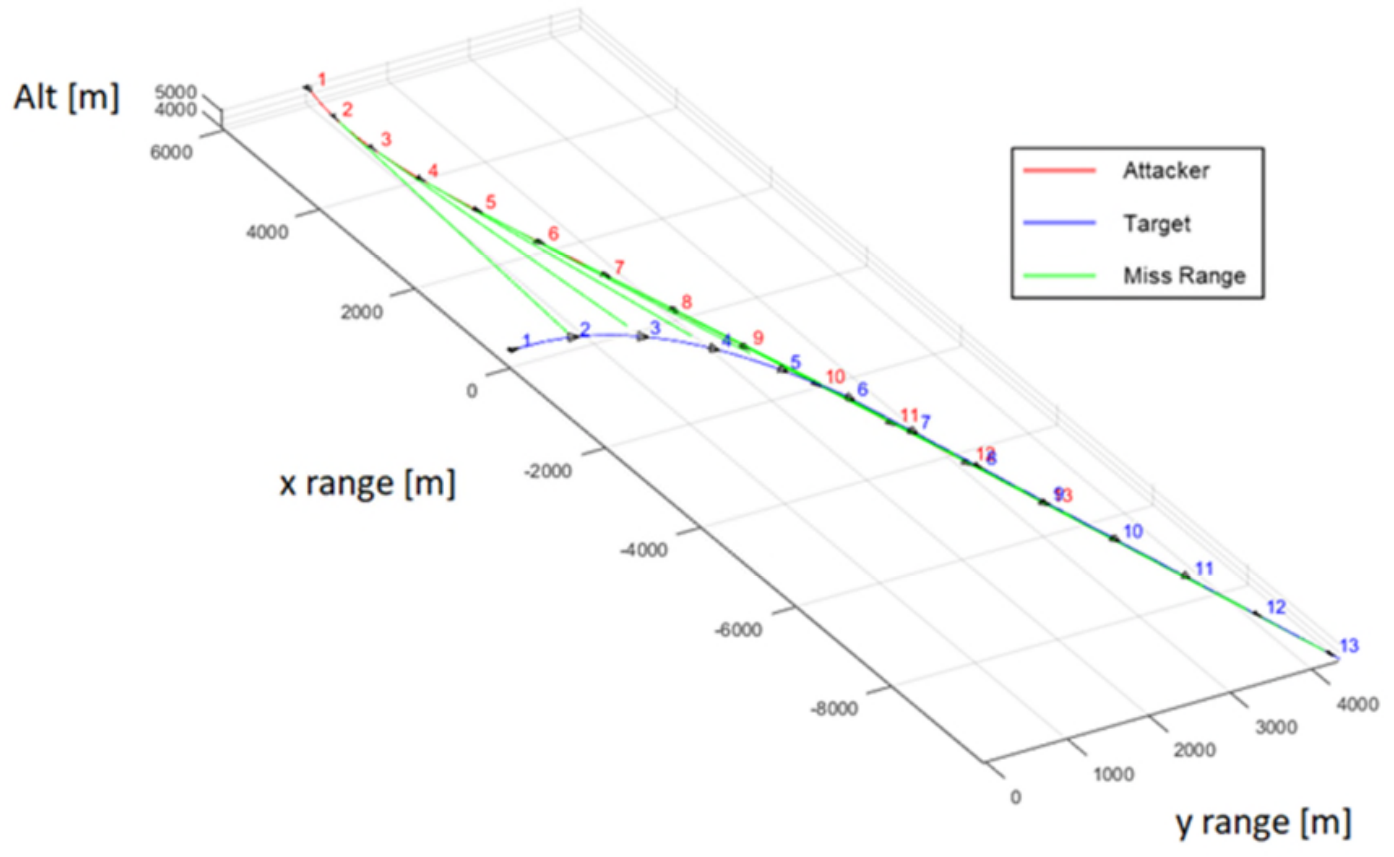

Figure 12: Schematic representation of a typical aircraft-vs-aircraft simulation scenario; the attacker is shown in red, the evader in blue and the green lines represent the missile's envelope.

\section{III.Application}

As an example application of the proposed methodology, a study on power plant effects on aircraft survivability was conducted, comparing the performance of the same airframe equipped with two different engines, one corresponding to a modern, high-performance turbofan engine and a second one simulating an older-generation version, sharing the same geometry. Error! Reference source not found. contains the main parameters of the two engine models:

Three test cases were specified, covering different areas of the aircraft's flight envelope, as per Table 4. Aircraft and missile parameters were kept constant for all engagement scenarios, as specified in this Paragraph. The study was subdivided in two parts addressing power plant effects on the survivability against missile and aircraft threats respectively. The results are presented in paragraphs III.D-III.E. 
Table 3: Engine Model Parameters

\begin{tabular}{rlccl}
\hline Parameter & & Engine 1 & Engine 2 & Description \\
\hline$\dot{m}_{S L S}$ & $=$ & $73 \mathrm{~kg} / \mathrm{s}$ & $73 \mathrm{~kg} / \mathrm{s}$ & Design Air Mass Flow \\
$P R_{F}$ & $=$ & 4.2 & 3.2 & Fan Pressure Ratio \\
$n_{F}$ & $=$ & 0.88 & 0.82 & Fan Isentropic Efficiency \\
$P R_{H P C}$ & $=$ & 5.95 & 4 & HP Compressor Pressure Ratio \\
$n_{H P C}$ & $=$ & 0.87 & 0.81 & HP Compressor Isentropic Efficiency \\
$C O T_{\text {max }}$ & $=$ & $1,700 \mathrm{~K}$ & $1,500 \mathrm{~K}$ & Maximum Combustor Outlet Temperature \\
$n_{H P T}$ & $=$ & 0.89 & 0.85 & HP Turbine Isentropic Efficiency \\
$n_{L P T}$ & $=$ & 0.9 & 0.85 & LP Turbine Isentropic Efficiency \\
$A B T_{\max }$ & $=$ & $2,000 \mathrm{~K}$ & $1,800 \mathrm{~K}$ & Maximum A/B Temperature \\
\hline \hline
\end{tabular}

Table 4: Test Case Specifications

\begin{tabular}{cccc}
\hline Test Case & & $\begin{array}{c}\text { Altitude } \\
{[\mathrm{m}]}\end{array}$ & Mach \\
\cline { 1 - 1 }$C_{1}$ & & 1,000 & 0.6 \\
$C_{2}$ & & 5,000 & 0.9 \\
$C_{3}$ & & 10,000 & 1.5 \\
\hline \hline
\end{tabular}

\section{Missile-vs-aircraft survivability}

Figures 13-15 present the calculated missile-vs-aircraft Lethal Zones (LZ) under flight conditions C1, C2 and C3: These were defined by the intersection between the lock-on range resulting from IR calculations and the missile kinematic envelope, as calculated from missile-vs-aircraft simulations. Results are presented in the form of missile Kinematic Lethal Zones (KLZ) against non-maneuvering (KLZ-NM) and maneuvering (KLZ-M) targets, along with Lock-On Zones (LOZ) for engine 1 (E1) and engine 2 (E2).

The left part of Figures 13-15 presents the missile envelopes against non-maneuvering aircraft cruising at the specified flight conditions: engine throttle setting was set so as to achieve constant-speed cruise for each aircraft/engine configuration. In these cases, it can be noted that the lock-on envelope bounds most of the missile envelope with the exception of an area at the rear of the aircraft where the envelope's limit is kinematic. Due to its greater efficiency, engine 1 has a lower exhaust temperature than engine 2 when generating the same thrust and, as a result, this leads to a smaller missile lethal envelope for engine 1 in cases $\mathrm{C} 1$ and $\mathrm{C} 2$. In case $\mathrm{C} 3$, both engines make use of the afterburner mode and have roughly the same exhaust temperature. With increasing altitude and Mach number, the airframe and engine exhaust become hotter and the atmospheric transmittance increases leading to an 
expansion of the aircraft lock-on range and, consequently, of the entire missile envelope. To add more, the kinematic envelope is also expanded due to the greater closure velocity between the missile and the aircraft along with the reduced drag of the missile resulting from the change in air density at higher altitudes.

The right part of Figures 13-15 presents the missile envelopes against maneuvering aircraft initialized at the specified flight conditions: in these cases, the maximum-power throttle setting was used to maximize aircraft maneuverability, leading to an expansion of the aircraft's lock-on envelope, to such an extent that it almost entirely covers the respective missile kinematic limit. Lock-on range is in this case larger for engine 1 , because of the higher afterburner temperature at maximum throttle. Evasive maneuvers were shown to have a significant effect on the missile's kinematic envelope, mainly in cases of front-quarter attacks, where, depending upon the flight condition a $30 \%$ reduction to the missile lethal range can be achieved. By comparing the results for the two engines (Figure 16) it was found that the propulsion system has little effect on the missile's kinematic envelope, since the exact same results were obtained in all cases for both engines despite a $20 \%$ thrust advantage of engine 1 compared to engine 2 . In the same context, it was found that non-zero values of $\mathrm{AOB}$ have a pronounced effect on the shape of the kinematic envelope, in agreement with qualitative data from the literature [19]. Under this scope, multiple runs were conducted at each flight condition to construct generalized missile envelopes accounting for these effects to be used for aircraftvs-aircraft studies. 

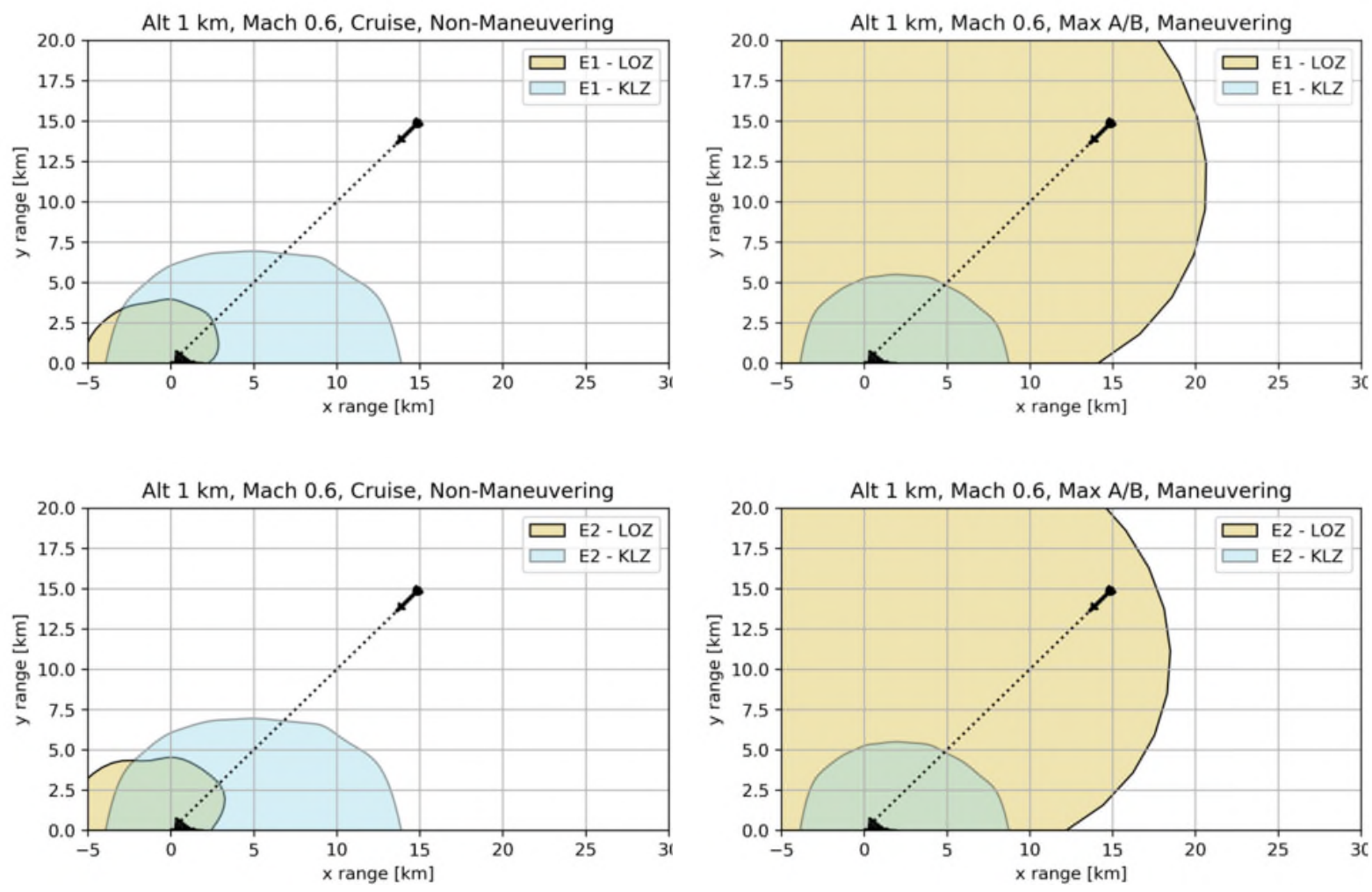

Figure 13: Flight Condition C1. Missile Kinematic Lethal Zones (KLZ) and Lock-On Zones (LOZ) against nonmaneuvering (left) and maneuvering aircraft (right). 

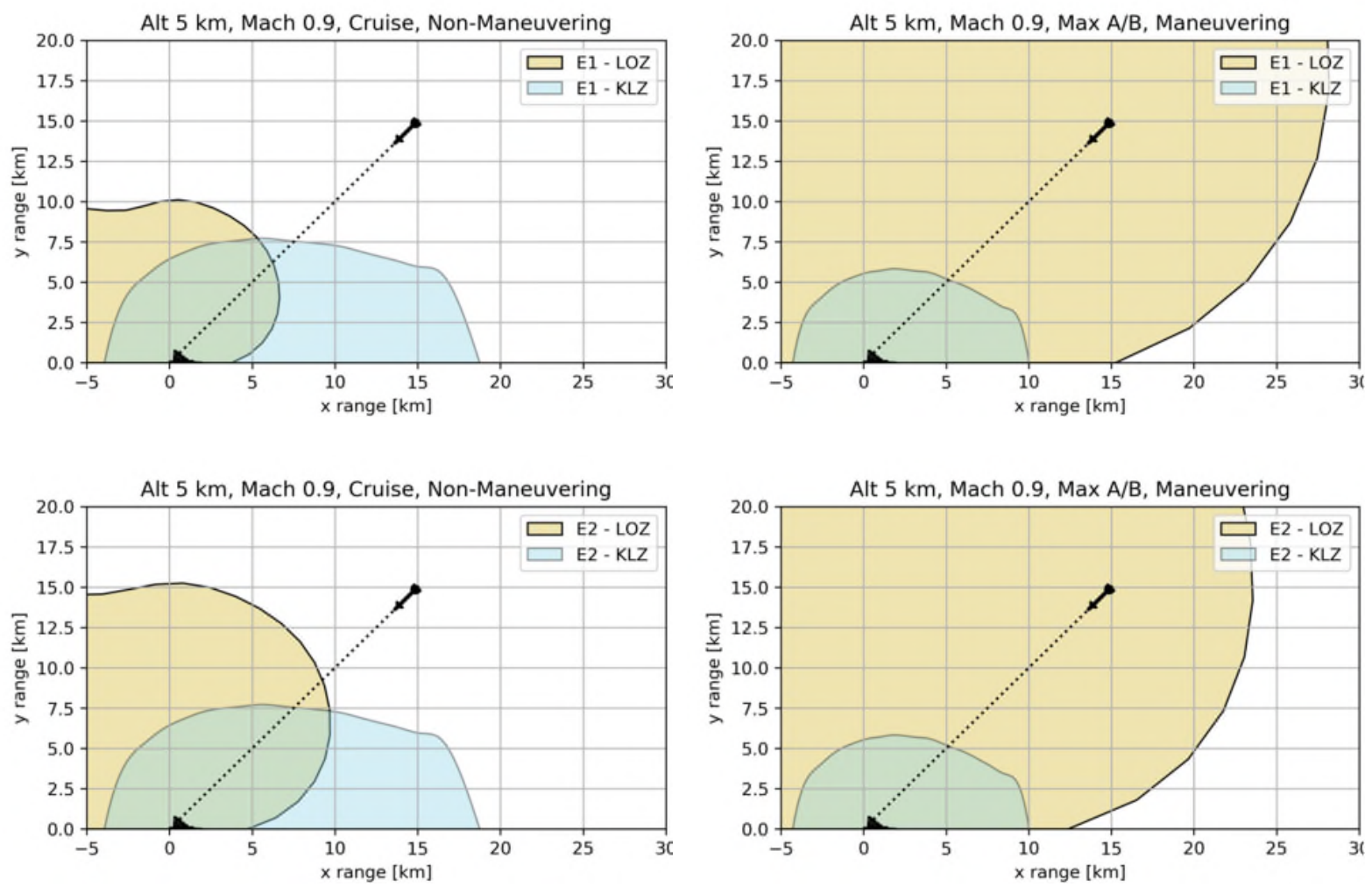

Figure 14: Flight Condition C2. Missile Kinematic Lethal Zones (KLZ) and Lock-On Zones (LOZ) against nonmaneuvering (left) and maneuvering aircraft (right). 

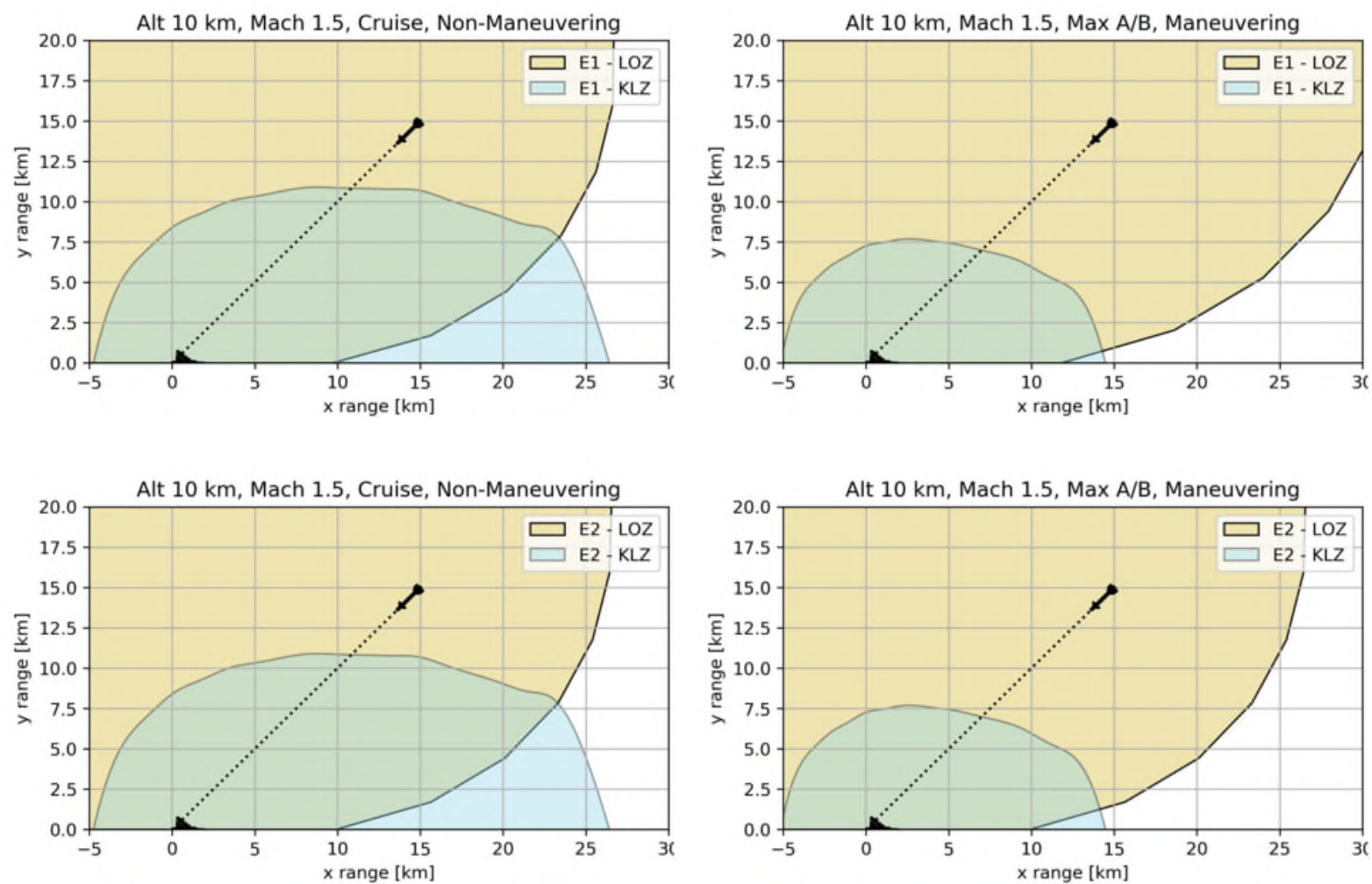

Figure 15: Flight Condition C3. Missile Kinematic Lethal Zones (KLZ) and Lock-On Zones (LOZ) against nonmaneuvering (left) and maneuvering aircraft (right).

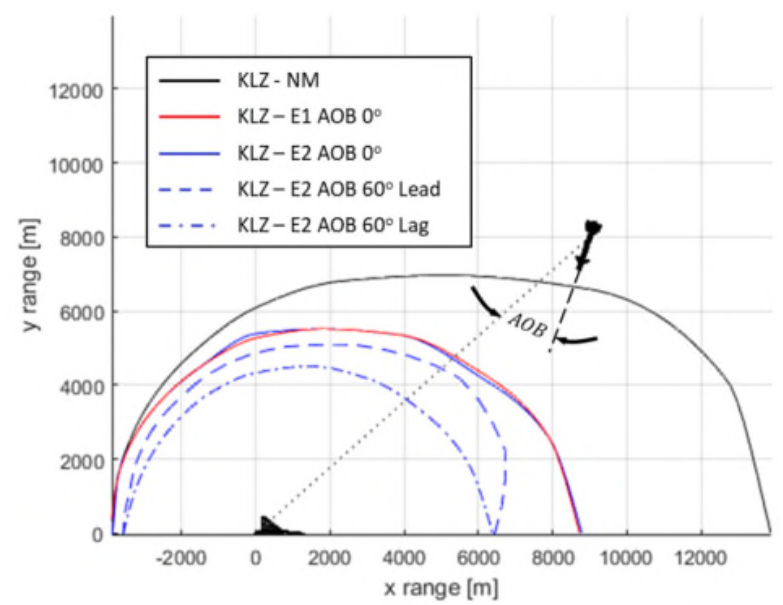

Figure 16: Flight Condition C1. Missile Kinematic Lethal Zones (KLZ) for various engine configurations and initial conditions. 


\section{E. Aircraft-vs-aircraft Survivability}

Using the missile envelopes generated by parametric runs of the missile-vs-aircraft scenario, the study was extended to the aircraft-vs-aircraft case. In order to construct equivalent lethal zones (named under the term Aircraft Lethal Zones - ALZ) for the latter case, both aircraft where initialized at the same altitude and airspeed with AOB set to zero. Both engine types (in all cases using the maximum power throttle setting to maximize maneuverability) were altered between the attacking and target aircraft to allow for an assessment of thrust effects on the size of the generated ALZs.

Figures 17-19 display the results obtained for various aircraft configurations and flight conditions C1-3 in comparison with the corresponding missile kinematic envelopes. To provide a common reference, cases with identical opponents are also presented: the latter unveil that the attacks from the frontal aspect provide the attacker with a positional advantage, leading to a local extension to the ALZ at the front with respect to the MLZ. The extent of this change depends upon the flight condition which defines the target's ability to turn away from the attacker without sacrificing speed: For this reason, a maximum occurs in case $\mathrm{C} 3$, in which, due to the supersonic initial conditions, closure velocity is high and the target's turn performance is lower than in the subsonic cases C1 \& C2. This approximately corresponds to $2.2 \mathrm{~km}$ of increase in ALZ for case C3 (Figure 19) compared to $0.9 \mathrm{~km}$ for case C1 (Figure 17) and 0.7 for case C2 (Figure 18).

A consistent finding within all the cases examined is that, contrary to the observations from the respective missilevs-aircraft scenarios, engine thrust has a clear effect on the aircraft's offensive and defensive capability. In terms of offence, thrust advantage is translated into an approximately uniform expansion of the ALZ around the target, which is more pronounced for rear-aspect attacks due to the attacker's ability to accelerate faster than the target and consequently attack from longer range. This effect is more evident in subsonic cases C1 (Figure 17) and C2 (Figure 18), whereas the difference is smaller in case C3 (Figure 19) in which, due to the supersonic flight condition, the difference in performance between the two engines is smaller (engine 2 has lower bypass ratio than engine 1). As far as the aircraft's defensive capability is concerned, a similar trend can be observed; in all cases engine 2-vs-engine 1 ALZs marginally extend beyond the corresponding MLZs, meaning that lower-thrust opponents only get chances to score kills in cases when the target does not maneuver until entering the attacker's missile envelope. Due to the smaller performance margin between the two engines in the supersonic regime, in case C3 the engine 2-vs-engine 1 ALZs are expanded approaching that for equal-thrust opponents (Figure 19). 


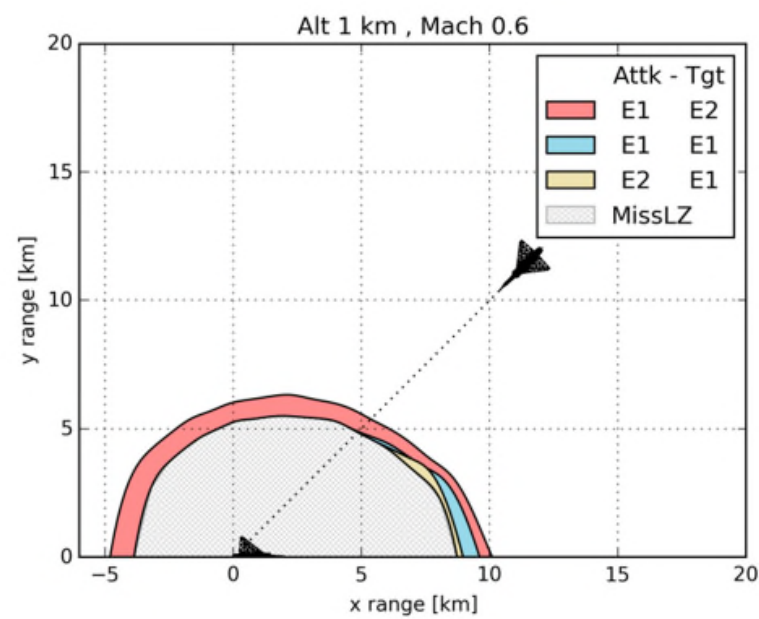

Figure 17: Flight Condition C1. Comparison between Aircraft Lethal Zones (ALZ) for different aircraft configurations.

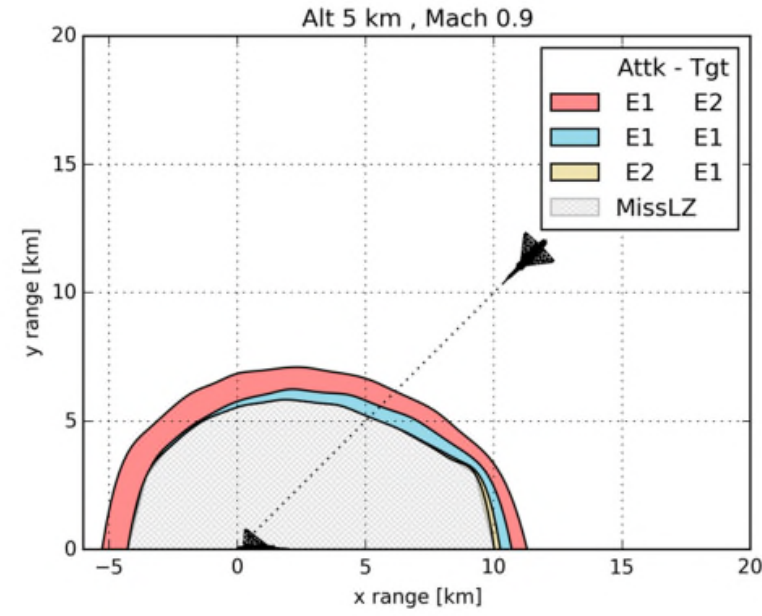

Figure 18: Flight Condition C2. Comparison between Aircraft Lethal Zones (ALZ) for different aircraft configurations. 


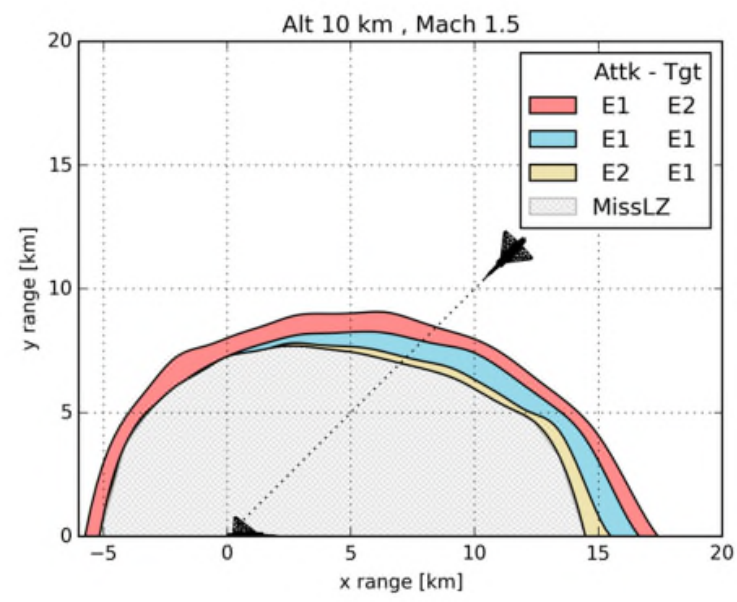

Figure 19: Flight Condition C3. Comparison between Aircraft Lethal Zones (ALZ) for different aircraft configurations.

\section{IV.Conclusion}

This article presented the development of a model for assessing aircraft survivability in an air-to-air combat scenario against opponents equipped with IR weapons. In this context, an aircraft IR signature model was introduced using a synthesis of semi-empirical methods for temperature estimation of the aircraft and the surrounding flowfield, Planck's radiation law and an atmospheric model. This was combined with missile \& aircraft kinematic simulation models to assess aircraft survivability by constructing missile-vs-aircraft and aircraft-vs-aircraft lethal zones for various air combat scenarios; power plant effects on aircraft's survivability were investigated by performing a comparison between the results obtained for configurations using different engine models.

The study unveiled that the performance of the target aircraft's propulsion system has essentially no effect on missile kinematic envelopes but does influence aircraft lock-on range which is related to the engine exhaust's temperature distribution. More fuel-efficient engines tend to generate lower IR emissions which lead to a reduction in the size of the missile's lethal zone. This reduces the aircraft's overall IRSL and, consequently, the probability of its being detected and attacked with IR-guided weapons on the course of a mission. The effect is more apparent at higher altitudes and high subsonic/transonic flight conditions, due to the higher throttle settings used during cruise and also because of the higher atmospheric transmittance which allows IR signals to travel greater distances. As the engine is switched to afterburning mode for air combat maneuvering, the aircraft lock-on envelope expands to such an extent 
that the missile's envelope is practically limited only by its kinematic performance. Effective aircraft evasive maneuvers were found to drastically reduce the missile's kinematic envelope, though this result is a function of the aircraft's instantaneous maneuverability and is practically unrelated to engine thrust performance.

As far as the aircraft-vs-aircraft cases are concerned, contrary to the respective missile-vs-aircraft scenarios, the engine's thrust performance was shown to have a measurable effect on the equivalent 'aircraft lethal zones' (ALZs), translated into both offensive and defensive advantages for aircraft with higher thrust over their opponents. These may be observed as a roughly uniform extension or shrinkage of ALZs around the target aircraft, the extent of which depends upon the thrust increment between the opponents at the examined flight condition. Among the configurations and flight conditions examined, the maximum ALZ expansion observed was $1 \mathrm{~km}$ compared to the equal-opponents case, whereas the corresponding ALZs of low-thrust attackers attacking higher-thrust targets were found to shrink down to approximately the size of the missile lethal zone.

\section{V.Future Work}

The results presented in this article addressed the topic of aircraft survivability, highlighting the effect of propulsion system performance on an aircraft's defensive and attacking capability in an air-to-air engagement scenario with IR-guided weapons. Further steps towards an improved understanding of these effects include the expansion of the study to RF-guided weapons and air-to-ground scenarios, which can be achieved with the addition of a model for aircraft RF-signature and a modification of the missile-VS-aircraft simulation conditions. In the same context, the modules comprising the presented methodology can be extended to take into account different aircraft geometries (such as non-axisymmetric, multi-flow nozzles and exhaust shielding/cooling) or replaced with higher-fidelity representations to allow for detailed studies on aircraft-propulsion system configurations. Ultimately, a combination of the above could lead to the introduction of a complete framework for interconnecting aircraft design and combat performance, reducing the cost and risk of new aircraft development projects. 


\section{References}

[1] J. White, "Aircraft Infrared Principles, Signatures, Threats and Countermeasures," NAWCWD TP 8773, Point Mugu, CA, 2012, DOI: 10.21236/ADA566304..

[2] F. Neri, Introduction to Electronic Defence Systems, 2nd ed, SciTech Publishing Inc, Raleigh, NC, 2001.

[3] J. Boyd, T. Christie and J. Gibson, "Energy-Maneuverability," Eglin AFB, FL, 1966.

[4] D. Cenciotti, "'Here's what I've learned so far dogfighting in the F-35": a JSF pilot's first-hand account," The Aviationist, [Online]. Available: https://theaviationist.com/2016/03/01/heres-what-ive-learned-so-fardogfighting-in-the-f-35-a-jsf-pilot-first-hand-account/. [Accessed 1st November 2016].

[5] J. Stillion, "Trends in Air-to-Air Combat: Implications for Future Air Superiority," Center for Strategic and Budgetary Assessment, 2015.

[6] R. Leinburger, Fighter, Bath, UK: Parragon Books Ltd, 2011.

[7] M. Arena, O. Younossi, K. Brancato, I. Blickstein and C. Grammich, "Why Has the Cost of Fixed-Wing Aircraft Risen?," RAND Corporation, Santa Monica, CA, 2008.

[8] J. Conant, J. Gruninger, T. Spaulding, T. Thompkins, G. Voltin and B. Sandford, "SPIRITS - A Model for Spectral Infrared Imaging of Targets and Scenes," in Proceedings of the 1985 IRIS Specialty Group Meeting on Targets, Backgrounds and Discrimination, ERIM IRIA Center, Ann Arbor, MI, 1985.

[9] G. Bishop, M. Caola, R. Geatches and N. Roberts, "SIRUS Spectral Signature Analysis Code," Proceedings of the SPIE, vol. 5075, pp. 256-269, 2003.

[10] M. Noah, J. Kristl, J. Schroeder and B. Sandford, "NIRATAM-NATO Infrared Air Target Model," Proceedings of SPIE, vol. 1479, pp. 275-282, 1991.

[11] S. Mahulikar, S. Sane, U. Gaitonde and A. Marathe, "Numerical Studies of Infrared Signature Levels of Complete Aircraft," The Aeronautical Journal, vol. 105, no. 1046, pp. 185-192, 2001, DOI: 10.1017/S0001924000025422.

[12] L. Jianwei and W. Qiang, "Aircraft-skin Infrared Radiation Characteristics Modeling and Analysis," Chinese Journal of Aeronautics, vol. 22, pp. 493-497, 2009, DOI: 10.1016/S1000-9361(08)60131-4.

[13] T. Kim, H. Lee, J. Bae, T. Kim, J. Cha, D. Jung and H. Cho, "Susceptibility of Combat Aircraft Modeled as an Anisotropic Source of Infrared Radiation," IEEE Transactions on Aerospcae and Electronic Systems, vol. 52, no. 5, pp. 2467-2476, 2015, DOI: 10.1109/TAES.2016.150513.

[14] G. Rao and S. Mahulikar, "New Criterion for Aircraft Susceptibility to Infrared Guided Missiles," Aerospace Science and Technology, vol. 9, no. 8, pp. 701-712, 2005, DOI: 10.1016/j.ast.2005.07.005.

[15] H. Sonawane and S. Mahulikar, "Tactical Air Warfare: Generic Model for Aircraft Susceptibility to Infrared Guided Missiles," Aerospace Science and Technology, vol. 15, pp. 249-260, 2011, DOI: 10.1016/j.ast.2010.07.008.

[16] H. Sonawane and S. Mahulikar, "Effect of Missile Turn Rate on Aircraft Susceptibility to Infrared-Guided Missile," Journal of Aircraft, vol. 50, no. 2, pp. 663-666, 2013, DOI: 10.2514/1.C031902.

[17] K. Andersson, "Modeling the Impact of Surface Emissivity on th Military Utility of Attack Aircraft," Aerospace Science and Technology, vol. 65, pp. 133-140, 2017, DOI: 10.1016/j.ast.2017.02.017.

[18] J. Boyd, "Aerial Attack Study," USAF Fighter Weapons School, 1960.

[19] R. L. Shaw, Fighter Combat: Tactics and Maneuvering, Annapolis, Maryland: United States Naval Institute, 1985.

[20] D. Alkaher and A. Moshaiov, "Dynamic-Escape-Zone to Avoid Energy-Bleeding Coasting Missile," Journal of Guidance, Control and Dynamics, vol. 38, no. 10, pp. 1908-1921, 2015, DOI: 10.2514/1.G000776.

[21] S. Ong and B. Pierson, "Optimal Planar Evasive Aircraft Maneuvers against Proportional Navigation Missiles," Journal of Guidance, Control and Dynamics, vol. 19, no. 6, pp. 1210-1215, 1996, DOI: 10.2514/3.21773.

[22] K. Virtanen, T. Raivio and P. Hamalainen, "An Influence Diagram Approach to One-on-One Air Combat," in 10th International Symposium on Dynamic Games and Applications, St Petersburg, Russia, 2002.

[23] K. Horie and B. Conway, "Optimal Fighter Pursuit-Evasion Maneuvers Found via Two-Sided Optimization," Journal of Guidance, Control and Dynamics, vol. 29, no. 1, pp. 105-112, 2006, DOI: 10.2514/1.3960. 
[24] J. Eklund, J. Sprinkle and S. Sastry, "Implementing and Testing a Nonlinear Model Predictive Tracking COntroller for Aerial Pursuit/Evasion Games on aa Fixed Wing Aircraft," in 2005 American Control Conference, Portland, OR.

[25] J. Sprinkle, J. Eklund, H. Kim and S. Sastry, "Encoding Aerial Pursuit/Evasion Games with Fixed Wing Aircraft into a Nonlinear Model Predictive Tracking Controller," in 43rd IEEE Conference on Decision and Control, Paradise Island, Bahamas, 2004, DOI: 10.1109/CDC.2004.1428851.

[26] D. You and D. Shim, "Design of an Aerial Combat Guidance Law Using Virtual Pursuit Point Concept," Proceeding of the Institution of Mechanical Engineers, Part G: Journal of Aerospace Engineering, vol. 229, no. 5, pp. 792-813, 2015, DOI: 10.1177/0954410014539654.

[27] Y. Baba and H. Takano, "Air Combat Guidance Law for UCAV," in AIAA 1st Technical Conference and Workshop on Unmanned Aerospace Vehicles, Portsmouth, VA, 2002, DOI: 10.2514/6.2002-3427.

[28] F. Imado, "Some Aspects of a Realistic Three-Dimensional Pursuit-Evasion Game," Journal of Guidance, Control and Dynamics, vol. 16, no. 2, pp. 289-293, 1993, DOI: 102514/3.21002.

[29] G. Burgin and L. Sidor, "Rule-Based Air Combat Simulation," NASA CR-4160, 1986.

[30] K. Yi, S. Baek, M. Kim, S. Lee and W. Kim, "The Effects of Heat Shielding in Jet Engine Exhaust Systems on Aircraft Survivability," Numerical Heat Transfer, Part A, vol. 66, pp. 89-106, 2014, DOI: 10.1080/10407782.2013.869441.

[31] S. Mahulikar, P. Kolhe and G. Rao, "Skin-Temperature Prediction of Aircraft Rear Fuselage with Multimode Thermal Model," Journal of Thermophysics and Heat Transfer, vol. 19, no. 1, pp. 114-124, 2005, DOI: $10.2514 / 1.6299$.

[32] D. Raymer, Aircraft Design: A Conceptual Approach, Fourth Edition, Blacksburg, VA: AIAA Education Series, 2006, DOI: $10.2514 / 4.104909$.

[33] ESDU 69011, "Heat Transfer by Forced Convection between a Two-Dimensional Turbulent Boundary Layer and a Smooth Flat Plate, with Application to Wedges, Cyliders and Cones," ESDU International.

[34] S. Mahulikar, H. Sonawane and G. Rao, "Infrared Signature Studies of Aerospace Vehicless," Progress in Aerospace Sciences, vol. 43, pp. 218-245, 2007, DOI: 10.1016/j.paerosci.2007.06.002.

[35] C. Bauer, A. Koch, F. Minutolo and P. Grenard, "Engineering Model for Rocket Exhaust Plumes Verified by CFD Results," in 29th ISTS, Nagoya, Japan, 2-9 June 2013.

[36] U. von Glahn, D. Groesbeck and J. Goodykoontz, "Velocity Decay and Acoustic Characteristics of Various Nozzle Geometries with Forward Velocity," NASA TM X-68259, Cleveland, OH, 1973, DOI: 10.2514/6.1973629.

[37] G. Abramovich, The Theory of Turbulent Jets, Cambridge, Massachusetts: The M.I.T. Press, 1963.

[38] USAF, "T.O. 1F-4E-1: USAF Series F-4E Aircraft Flight Manual," USAF, 1979.

[39] C. An, D. Kang, S. Baek, Myong R.S., W. Kim and S. Choi, "Analysis of Plume Infrared Signatures of S-Shaped Nozzle Configurations of Aerial Vehicle," Journal of Aircraft, vol. 53, pp. 1768-1778, 2016, DOI: 10.2514/1.C033685.

[40] T. Triantafyllou, T. Nikolaidis, M. Diakostefanis and P. Pilidis, "Numerical Simulation of the Airflow over a Military Aicraft with Active Intake," Proceedings of the Institution of Mechanical Engineers, Part G: Journal of Aerospace Engineering, vol. 8, no. 231, pp. 1369-1390, 2017, DOI: 10.1177/0954410016651294.

[41] N. Gross, G. Blaisdell and A. Lyrintzis, "Evaluation of Turbulence Model Corrections for Supersonic Jets using the OVERFLOW Code," in 40th Fluid Dynamics Conference and Exhibit, Chicago, IL, 26 June - 1 July 2010, DOI: 10.2514/6.2010-4604.

[42] S. Baqar, "Low-Cost PC-baed High-Fidelity Infrared Signature Modelling and Simulation," PhD thesis, Dept. of Aerospace, Power and Sensors, Defence College of Management and Technology, Crranfield University, 2007.

[43] T. Nikolaidis, "The TURBOMATCH 2.0 Scheme for Gas Turbine Performance Calculations," unpublished software manual, Cranfield University, Cranfield, UK, 2015.

[44] J. Kennedy and R. Eberhart, "Particle swarm optimization," in Proceedings of IEEE International Conference on Neural Networks 4, Piscataway, New Jersey, 1995. 
2019-07-03

\section{Effects of propulsion system operation on military aircraft survivability}

Antonakis, Aristeidis

American Institute of Aeronautics and Astronautics

Antonakis A, Nikolaidis T, Pilidis P. (2019) Effects of propulsion system operation on military aircraft survivability. Journal of Aircraft, Volume 56, Issue 6, November 2019, pp. 2131-2143

https://doi.org/10.2514/1.C035508

Downloaded from Cranfield Library Services E-Repository 